\title{
Study of depressive disorders in the patients infected by HIV
}

\author{
Katabwa Kabongo ${ }^{1 *}$, Mutombo ${ }^{2}$, Tshibangu Manyonga $\mathrm{E}^{3}$, Ntambwe Mwembo $\mathrm{A}^{4}$, Wembonyama $\mathrm{S}^{5}$ and Mukendi Kavulu $\mathrm{R}^{6}$ \\ ${ }^{1}$ Department of Internal Medicine, University of Lubumbashi, Democratic Republic of the Congo \\ ${ }^{2}$ Department of Neurology, University of Mbuji Mayi, Democratic Republic of the Congo \\ ${ }^{3}$ Department of Psychology, Centre excellence UNILU, University of Lubumbashi, Democratic Republic of the Congo \\ ${ }^{4}$ Department of Pediatrics, University of Lubumbashi, Democratic Republic of the Congo \\ ${ }^{5}$ Department of Public Health, University of Lubumbashi, Democratic Republic of the Congo \\ ${ }^{6}$ Neurologist, complex hospital regional of Mons, St Joseph, Catholic University of Leuven, Belgium
}

\begin{abstract}
Introduction: Depression is the most common mental health problem for people with HIV/AIDS in Africa, the announcement of the disease, the binding processing; relational difficulties with the surroundings contribute to the installation of this mood disorder.

The objective of our study is to identify the impact of depressive disorders in HIV infection in our patients.

Methodology: This is a cross-sectional study at the center of excellence for 4 months. 50 patients adhere to treatment ARV since more than 6 months were submitted to a questionnaire specialized depression, Depression of Beck (BDI) inventory, informed consent was required.

Results: 50 patients were part of our study with female $62 \%$ for a sex ratio $\mathrm{F} / \mathrm{H} 1.6 .26 \%$ of the participants are officials compared to $74 \%$ of persons exercising a liberal profession,

The predominant level of study is secondary or $68 \%$ of our patients. Compared assessment of depression by the BDI, $46 \%$ of patients showed signs of depression which $8 \%$ of our patients showed signs of major depression with a suicidality of $25 \%$ compared with $12 \%$ of average depression signs.

Conclusion: Depressive disorders during HIV infection represent a real danger for the care of patients; several biopsychosocial factors can explain their occurrence.

During our survey $46 \%$ of the participants showed signs of depression and among them $8 \%$ of major form with a rate of suicidality by $25 \%$.
\end{abstract}

\section{Introduction}

HIV infection is now recognized as a chronic disease and binding treatment, fear of a deterioration in his State of health, the difficulty in establishing intimate relationships, are weighing on the shoulders of patients. Property that 2 people on 3 with HIV live in Sub-Sahelian Africa, [1] most of what we know about the relationship between HIV and depression comes from research conducted in North America and Europe, very few studies have been conducted in our midst. Depression is not a commonplace phenomenon in patients infected with HIV, but a real disease that deserves adequate support; it can obviously have an influence on the adherence to treatment and therefore on the quality and the life expectancy of patients. This is why all feelings of sadness, lack of courage, black idea must be communicated to the physician.

Several etiological bio-psycho-social factors have been advanced to explain the emergence of a depressive mood disorder in patients with HIV. First, the psychological impact of the discovery of its serology, experience it through time and the progression of the disease once declared AIDS, affective reactions are extremely varied and depends on several factors including the personality of the patient, psychiatric history and the quality of the response of his emotional surroundings [2]. The consequences on the thymie can be transient or prolonged ranging from reactive depressive disorder to severe depressive States.
Uncertainty over the evolution and the response to treatment, the consequences on sexuality and the fear of social exclusion appear also as important to take into account [3] dimensions.

On a neurological level, the central nervous systems HIV neurotropism led to neuro-pathological changes particularly at the level of some grey matter structures. On the other hand, these patients show a decrease in the concentrations of tryptophan which, associated with a decrease in serotonin biosynthesis, led a drop in level of this neurotransmitter [4].

In the stages of the disease, endocrine, metabolic and neurological disorders can aggravate or induce a depressive disorder. Similarly, medications such as some anti-retroviral and corticosteroids can also present as adverse effect a disruption of the [4] thymie.

The objective of our work is to identify the impact of depressive

Correspondence to: Katabwa Kabongo J, Department of Internal Medicine, University of Lubumbashi, Democratic Republic of the Congo, Tel: + 2439970 17 104; E-mail: joekabongo2004@gmail.com

Received: October 01, 2016; Accepted: October 12, 2016; Published: October 17,2016 
disorders in HIV infection, more specifically to determine the incidence of depression and suicidality in our cohort of HIV-infected patients.

\section{Methodology}

This is a cross-sectional study Center of excellence at the University of Lubumbashi (CEU) over a period of four months from January 10, 2013, to April 20, 2013, on 50 patient's adherent to the anti-retroviral (ARV) treatment for 6 months.

Our study population consists of persons living with HIV/AIDS (PL HIV) (PLHA) under treatment anti-retroviral for at least 6 months, acceding to the treatment and consent to answer our questionnaire. The inclusions are strict conditions have been admitted to study, only patients with good compliance and adherence to treatment i.e., hours of catch of drugs and the quantities required.

Fifty patients were recruited according to the behavior displayed at the announcement of the diagnosis as well all those who submitted to at the outset a diagnostic denial caught our attention and have undergone this evaluation 6 months after properly observing the treatment.

For the harvest data, we used a survey questionnaire with sociodemographic data, inventory of depression of Beck (BDI), which is an instrument containing 13 item and a question to assess the psychological person and we state to diagnose depression and determine the degree. The rating of each item varies from 0-3 so (minimum $=0$ and maximum $=3$ ) The total score is obtained from the sum of score of each question and varies from zero to sixty-three and its interpretation is as follows: no depression $=$ lower when the score is less than 11. mild depression score between 12 and 19; Depression average between 20 and 26, and major depression or severe score is beyond 26 [5]. This questionnaire is written in French and like many of our respondents do not well master the French language, the questionnaire was translated into local language, Kiswahili.

\section{Analysis of the data}

The data collected from variables: sex, age, marital status, weight, occupation, level of study and degree of depression were encoded on Excel and analyzed by the software epi info (7) and the presentation of the results we used plain tables varied and diverse bi then used as statistical test: chi square.

\section{Results}

Female represents $62 \%$ against $38 \%$ of male with a sex ratio of $\mathrm{F} / \mathrm{H}$ $1.674 \%$ of the population of our sample are a liberal work and $26 \%$ of employees. Married persons make up 52\% and $24 \%$ of people are divorced. The municipality of Kampemba comes out on top with $26 \%$. $68 \%$ of our patients have a level of secondary education. The age group of [33-43(0. 40\% with an average age of 47,22 .)] (Table 1) (people living with HIV).

Assessment by the Beck depression inventory gives $46 \%$ of PLHIV with symptoms depressive. $26 \%$ for mild depression, $12 \%$ for the average and $8 \%$ for major depression. Suicidality is $25 \%$ the population with major depression (Table 2).

We have noted no significant difference in our patients with depression, compared to the sex, level of education or even their profession (Table 3$)$.

\section{Discussion}

Depression is the most common mental health problem for people
Table 1. Socio demographic characteristics.

\begin{tabular}{|c|c|c|}
\hline \multicolumn{3}{|c|}{ Socio Demographic Characteristics } \\
\hline Sex & Frequency & Pierce \\
\hline Male & 19 & $38.00 \%$ \\
\hline Female & 31 & $62.00 \%$ \\
\hline \multicolumn{3}{|l|}{ Profession } \\
\hline Official & 13 & $26.00 \%$ \\
\hline Liberal & 37 & $74.00 \%$ \\
\hline \multicolumn{3}{|l|}{ Civil status } \\
\hline Single & 4 & $8.00 \%$ \\
\hline Divorce (e) & 12 & $24,00 \%$ \\
\hline Marie (e) & 26 & $52.00 \%$ \\
\hline Widowed & 8 & $16.00 \%$ \\
\hline \multicolumn{3}{|l|}{ Provenance } \\
\hline Annex & 9 & $18.00 \%$ \\
\hline Kamalondo & 3 & $6.00 \%$ \\
\hline Kampemba & 13 & $26.00 \%$ \\
\hline Katuba & 7 & $14.00 \%$ \\
\hline Kenya & 7 & $14.00 \%$ \\
\hline Lubumbashi & 8 & $16.00 \%$ \\
\hline Ruashi & 3 & $6.00 \%$ \\
\hline \multicolumn{3}{|l|}{ Level of study } \\
\hline None & 8 & $16.00 \%$ \\
\hline Primary & 6 & $12.00 \%$ \\
\hline Secondary & 34 & $68.00 \%$ \\
\hline SUP or University & 2 & $4.00 \%$ \\
\hline
\end{tabular}

Table 2. Distribution of PLHA according to depression and suicidal risk.

\begin{tabular}{|l|c|c|}
\hline Depression $(\mathbf{n}=\mathbf{5 0})$ & Frequency & Pierce \\
\hline Yes & 23 & $46.00 \%$ \\
\hline Non & 27 & $54.00 \%$ \\
\hline Level Depression $(\mathbf{n}=\mathbf{5 0})$ & & \\
\hline Mild depression & 13 & $26.00 \%$ \\
\hline Major depression & 4 & $8.00 \%$ \\
\hline Depression mean & 6 & $12.00 \%$ \\
\hline Not depressed & 27 & $54.00 \%$ \\
\hline Major depression & & \\
\hline Risk suicidal (n= 4) & & \\
\hline Yes & 1 & $25.00 \%$ \\
\hline Non & 3 & $75.00 \%$ \\
\hline Total & 4 & $100.00 \%$ \\
\hline
\end{tabular}

Table 3. Depression associated to sociodemographic.

\begin{tabular}{|c|c|c|c|c|}
\hline \multicolumn{5}{|c|}{ DEPRESSION (2) } \\
\hline $\operatorname{Sex}(n=50)$ & & Depressed $(n=23)$ & Not depressed $(n=27)$ & TOTAL \\
\hline \multirow[t]{2}{*}{ Male } & Neither & 10 & 9 & 19 \\
\hline & $\%$ & 43.5 & 33.3 & 38 \\
\hline \multirow[t]{2}{*}{ Female } & Neither & 13 & 18 & 31 \\
\hline & $\%$ & 56.5 & 66.7 & 62 \\
\hline \multicolumn{5}{|c|}{ Statement $(n=50)$} \\
\hline \multirow[t]{2}{*}{ Non } & Neither & 4 & 4 & 8 \\
\hline & $\%$ & 17.4 & 14.8 & 16 \\
\hline \multirow[t]{2}{*}{ Yes } & Neither & 19 & 23 & 42 \\
\hline & $\%$ & 82.6 & 85.2 & 84 \\
\hline \multicolumn{5}{|c|}{ Profession $(\mathrm{n}=\mathbf{5 0})$} \\
\hline \multirow[t]{2}{*}{ Official } & Neither & 6 & 7 & 13 \\
\hline & $\%$ & 26.1 & 25.9 & 26 \\
\hline \multirow[t]{2}{*}{ Liberal } & Neither & 17 & 20 & 37 \\
\hline & $\%$ & 73.9 & 74.1 & 74 \\
\hline \multirow[t]{2}{*}{ TOTAL } & Neither & 23 & 27 & 50 \\
\hline & $\%$ & 100 & 100 & 100 \\
\hline
\end{tabular}


infected with HIV in Africa; multiple studies have been done over the past years to elucidate the question.

The study of Lubumbashi at the center of excellence focused on 50 patients and followed since the announcement of the diagnosis for 6 months. It must be said that Congolese literature is characterized by the scarcity of these kinds of studies, which has led our team to focus more closely on people living with HIV (PLHIV) PLHIA with a denial diagnostic at the start and having developed subsequently depressive symptoms with suicidal risk obvious. Many studies in different countries have shown that HIV-positive people had high levels of depression; a Zambian study shows that $85 \%$ of HIV-positive pregnant women have had severe depression and suicidal thoughts [6]. In the study Uganda carried out by 'The AIDS Support Organization (TASO)' at the Hospital of Mulago in Kampala, 54.3\% of the participants met the criteria of severe depression [7]. hospital Typerberg in Cape Town in South Africa, $38.1 \%$ of black and mestizo HIV-positive patients have the corresponding criteria for the diagnosis of depression. 19\% of women had a history of depression before being diagnosed with HIV and $11 \%$ was considered in danger of suicide [8].

The female sex is leading with $62 \%$ of the patients for a sex ratio $\mathrm{F} / \mathrm{H} \mathrm{1.6}$; This high rate of women is a reflection of our cohort that it comprises $65 \%$ of women, in our environment much of middle-class men fled into hiding and are treated by doctors directly in their offices, and so in official channels very little man appear, much of the time those in lower social class; as women they are only recruited at the prenatal or Pediatrics when they come with sick children, it is difficult to announce to their husbands, while themselves generally through the phase of diagnostic denial.

$38 \%$ of our study population is unemployed, or under employee, here with us most is engaged in a liberal profession, a factor for social instability.

A number of factors that could increase the risk of depression in people living with HIV/AIDS in Africa have been identified, these risk factors are: more negative life events, unintended pregnancy, more stress and a failure to achieve family or social obligations [9-11].

Many people in Africa live in extreme poverty, it was associated with the high prevalence of HIV. In South Africa there is obviously a correlation between poverty and the degradation of mental health [12]. Depression has been associated with a number of indicators of financial insecurities, as for example do not have a personal income and the absence of a regular household income [12].

According to the "Psychiatric Problems of HIV/AIDS and their Management in Africa" (psychiatric problems of HIV/AIDS and governance in Africa): [12] "the clinical manifestation of depression in people with HIV/AIDS in an African place includes feelings of hopelessness, despondency and isolation with themes of guilt, remorse, fear of punishment and suicidal thoughts. Often, patients have somatic complaints, including various ailments and secondary attention decreased slowness in ideation, sleep disturbance, anorexia and they are more restless and more edgy. There is also paranoid suicidal: very frequent accusations of witchcraft [12].

After evaluation by the inventory of the depression of Beck, $46 \%$ of our study population shows signs of depression in the following proportions: $26 \%$ for minor depression, $12 \%$ for the average depression and $8 \%$ for severe depression with suicidal risk of $25 \%$ in patients with major depression, it must be said that despite the efforts provides the centre of excellence at the University of Lubumbashi to develop a Department able to manage psychosocial follow-up to the better counselling of newly enrolled patients, the problem of diagnosis remains complicated by its singularity and given also the context of stigma and discrimination in our midst [13] the traumatic effect of the announcement of the patients is also accentuated by health professionals defence mechanisms such as projective identification, false reassurance and headlong rush forward. Turn this patient isolation, denial or even regression [12], which are precursors of the symptomatology depressed this might involve social, generally low attainment in most times and finally often poor social interaction in our midst [13].

$25 \%$ of patients have major depression with a suicidality in our study, which usually results in a high-risk sexual behaviour, 'the person prefers to bring in his grave many other by infecting' the larger share of these patients refuse to adhere to treatment and some advanced even refuse to eat properly.

Breitbart, et al. showed that patients voicing a desire for assisted suicide, it was more related to the presence of depression and despair to the intensity of pain, physical symptoms or disease [2] evolutionary time. In addition, suicidality can be a complication in the patient with dementia-AIDS (CDS) complex whose symptoms and frequent psychiatric signs are a labile mood, disinhibited behavior, cognitive disorders and an increased impulsivity [14]. HIV/AIDS patients finally have a seven times greater risk of suicide than patients with other diseases such as cancer, multiple sclerosis or Huntington's disease who present themselves respectively 4.3 and 2 times higher risk than the general population [12].

Suicidal ideation, suicide attempts and successful suicide are frequent complications in these patients. The first study on suicide risk was estimated the relative risk of suicide to 66,15 times higher than in the general population and 36 times more than patients without AIDS [2]. During the next two decades, a progressive decrease in the risk of suicide among these patients was observed [15]. The factors involved in this development were new drug anti-retroviral, better prophylaxis of opportunistic infections, the diagnosis and treatment of psychiatric complications as well as any social stigma of the disease. As suicidal ideation, the results of some studies show no difference between the different stages of the infection while others are the period immediately following the discovery of HIV as the moment of maximum risk [16]. on the other hand, other authors combine more suicidal ideation psychological variables and current stressors as being HIV-positive [17] for suicide attempts, most of the work have highlighted that the presence or the absence of psychiatric comorbidity, substance abuse and the history of attempted suicide were more predictive than the HIV positive in itself factors [18].

\section{Conclusion}

Depressive disorders during HIV infection represent a problem for the support of PLHIV. $46 \%$ of our patients have depressive symptoms with a suicidality of $25 \%$ of those with major depression; This should attract the attention of providers on the sexual behavior of our patients, often at risk and on the issue of adhesion and adherence to treatment that are a reflection of the depressive symptomatology to be systematically search by a suitable tool.

\section{References}

1. Freeman M (2004) HIV/AIDS in developing countries: Heading towards a mental health and consequent social disaster. S Afr J Psychol 34: 139-159.

2. Brandt R (2008) The mental health of people living with HIV/AIDS in Africa: A systematic review. Centre for Social Science Research, Cape Town. 
3. Kwalombota M (2002) The effect of pregnancy in HIV-infected women. AIDS Care 14: 431-433.[Crossref]

4. Petrushkin H, Boardman J, Ovuga E(2005) Psychiatric disorders in HIV-positive individuals in urban Uganda. Psychiatric Bulletin 29: 455-458.

5. Beck AT (1988) An inventory for measuring clinical anxiety: psychometric properties. J Consult Clin Psychol 56: 893-897. [Crossref]

6. Olley BO (2006) Psychological distress in the first year after diagnosis of HIV infection among women in South Africa. Afr J AIDS Res 5: 207-215.[Crossref]

7. Ciesla JA, Roberts JE (2001) Meta-analysis of the relationship between HIV infection and risk for depressive disorders. Am J Psychiatry 158: 725-730.[Crossref]

8. Sanchez-valero C (2003)Dépression et VIH/sida. Revue Médicale Suisse.

9. Marzuk PM, Tierney H, Tardiff K, Gross EM, Morgan EB, et al. (1988) Increased risk of suicide in persons with AIDS. JAMA 259: 1333-1337.[Crossref]

10. Coté TR, Biggar RJ, Dannenberg AL (1992) Risk of suicide among persons with AIDS. A national assessment. JAMA 268: 2066-2068.[Crossref]
11. Komiti A, Judd F, Grech P, Mijch A, Hoy J, et al. (2001) Suicidal behaviour in people with HIV/AIDS: a review. Aust $N Z J$ Psychiatry 35: 747-757.[Crossref]

12. Musisi S, kinyanda E (2009) Psychiatric problems of HIV/AIDS and their management in Africa, Kampala.

13. Joe Kabongo, La gestion(2013) De l'effet de l'annonce. IBN 3: 13-15

14. Kelly K (2001) Relationships among maternal-fetal attachment, prenatal depression, and health practices in pregnancy. Res Nurs Health 24: 203-217. [Crossref]

15. Consoli SG, Ferrand I (1989) Manifestations psychiatriques de l'infection à VIH EncyclopédieMédico-Chirurgicale. Paris.

16. Breitbart W, Rosenfeld BD, Passik SD (1996) Interest in physician-assisted suicide among ambulatory HIV-infected patients. Am J Psychiatry 153: 238-242.[Crossref]

17. Alfonso CA, Cohen MA (1994) HIV-dementia and suicide. Gen Hosp Psychiatry 16 : 45-46.[Crossref]

18. Harris EC, Barraclough BM (1994) Suicide as an outcome for medical disorders. Medicine (Baltimore) 73: 281-296.[Crossref]

Copyright: (C2016 Katabwa Kabongo J. This is an open-access article distributed under the terms of the Creative Commons Attribution License, which permits unrestricted use, distribution, and reproduction in any medium, provided the original author and source are credited. 